\title{
Influence of Colour Grading on seed and seedling quality characters of Sesamum indicum
}

\author{
N. Suma ,P. Srimathi . \\ Department of Seed Science and Technology, Tamilnadu Agricultural University, Coimbatore-6
}

\begin{abstract}
The colour variation available in gingelly seed was found to be three, which was black, brown and cream colour which constitute the seed lot by 64, 24 and 19 per cent respectively and that seeds with dark brown colour registered better seed quality characters due to their better stamina in physical, physiological and biochemical phenomenon.
\end{abstract}

Keywords:colour,sesame,seedquality,grading

\section{Introduction}

Sesame (Sesamum indicum L.), thought to have originated from Africa, is considered to be the oldest oilseed crop known to man and is now grown in many parts of the world. . Basically sesamum seeds are yellowish, red, or black in colour. These tiny, flat seeds are also available in shades of brown, red and black but those most commonly found are pale grayish-ivory. More than 80 per cent of the crop is cultivated in kharif and a small quantity is cultivated in rabi . Therefore, sesame seed is available throughout the year in the country.The fatty acid composition of sesame oil varies considerably among the different cultivars worldwide (Yermanos et al. 1972; Brar 1982)

\section{Materials And Methods}

Genetically pure seeds of sesamum (Sesamum indium.) cv. CO1 obtained from Department of oilseeds, TNAU, Coimbatore, formed the base material for the study. The field experiments and laboratory experiments were conducted at Department of Seed Science and Technology, Tamil Nadu Agricultural University, Coimbatore $\left(11^{\circ} \mathrm{N}\right.$ latitude and $77^{\circ} \mathrm{E}$ longitude with an altitude of $427 \mathrm{~m}$ above mean sea level) during 2004-2005

The precleaned seeds of sesamum were separated based on colour by visual observation on the basis of Munsell soil colour chart as black, brown and reddish yellow. The seed samples drawn from each treatment were evaluated for the seed and seedling quality characters as

\section{Seed recovery $(\%)$}

The weight of seeds retained in each sieve was recorded and seed recovery was calculated in percentage using the following formula

Seed recovery $(\%)=$

Weight of seeds retained in each sieve

Total weight of seeds

\section{0 seed weight $(\mathbf{m g})$}

Eight replicates of hundred seeds were drawn from each treatment, weighed in sensitive electronic balance and expressed in milligrams (ISTA, 1999).

\section{Germination (\%)}

Four replicates of hundred seeds were sown in sand medium and kept under the test conditions of $25^{\circ} \pm$ $1^{\circ} \mathrm{C}$ and $95^{\circ} \pm 3$ per cent relative humidity maintained in a germination room illuminated with fluorescent light. After the test period of seven days the normal seedlings were counted and the mean values expressed as percentage (ISTA, 1999) to the total number of seeds placed for germination.

\section{Root length (cm)}

At the time of germination count, ten normal seedlings were taken at random. The length between the collar and tip of the primary root was measured as root length and the mean length expressed in centimeter.

\section{Shoot length $(\mathbf{c m})$}

From the ten seedlings used for measuring the root length, the length between collar and tip of the primary shoot was measured as shoot length and the mean value expressed in centimeter. 


\section{Drymatter production (mg 10 seedlings $^{-1}$ )}

Ten normal seedlings from the germination test were selected at random, dried in a hot air oven maintained at $85^{\circ} \mathrm{C}$ for $48 \mathrm{~h}$ and cooled in a desiccators for 30 minutes, and weighed in an electronic digital balance. The mean weight was expressed as dry matter production 10 seedlings $^{-1}$ in milligram (Gupta, 1993).

\section{Vigour index}

The Vigour index values were computed, adopting the procedure of Abdul-Baki and Anderson (1973) as given below and expressed as whole number.

Vigour index $=$ Germination $(\%) \mathrm{x}$ Total seedling length $(\mathrm{cm})$

\section{Results And Disccusion}

Highly significant results were obtained due to colour grading for the evaluated seed and seedling quality characters (Table 1)

Seed coat is one of unique genetic factor that varies with crop in most cases and sometimes with varieties. Seed researchers have also coined seed coat colour as a factor of seed quality (Dharmalingam, 1989; Rajasekaran, 1997 and Vakeswaran, 1998) and related the seed coat colour variation to seed quality variations. The colour variation available in gingelly seed was found to be black, brown and cream colour which constitute the seed lot by 64, 24 and19 per cent respectively.(Fig. 1) The physical and physiological seed quality parameters evaluated viz., 100 seed weight, germination, root length, shoot length , drymatter production and vigour index values respectively registered $3,4,5,2,6$ and 8 per cent increased values for black coloured seed compared to bulk seed. The performance of cream colour seed was even lesser than bulk seed recording 32,6 , $4,8,4$ and 10 per cent reduction in values for 100 seed weight, germination, root length, shoot length, drymatterproduction andvigour index, respectively. Baumunk-Wende (1981) in peas, Singh and Gill (1983), Patil et al. (1987) in bhendi, Radha (1991) in Tephrosiapurpurea and Vakeswaran (1998) in peas also observed similar seed quality variations due to seed coat colour. Apart from the genetic variation of seed colour, the off colours of genetic colour occur either due to the seasonal variations or due to rain / high relative humidity (Dharmalingam, 1989) or influence of maturity status of seed (Parameswari, 1999) or due to onset of ageing (Srimathi, 1997). However, the present investigation highlighted that seeds with black followed by dark brown colour registered better seed quality characters due to their better stamina in physical, physiological and biochemical phenomenon. Thus the study reveals that black coloured seeds were better in seed quality characters.

\section{References}

[1]. Abbul - Baki, A.A. and J.D. Anderson,. 1973 Vigour determination in soybean seed by multiple criteria. Crop Sci., 13: 630-633.

[2]. Baumunk-Wende, E. 1981. Correlation between colour of testa and vigpir of seeds in wrinkled peas. Acta. Hort., 111(2) : 25-33.

[3]. Dharmalingam, C. and A. Vijayakumar 1991. Seed quality in relation to fruit to fruit size in acid lime South Indian Hort., 35 (4) :274-279.

[4]. Gupta, P.C. 1993. Seed vigour testing. Handbook of seed testing. Quality control and research Dev.,

[5]. ISTA. 1999, International Rules for Seed testing. Seed Sci. \& Technol. (Supplement Rules) 27: 25-30.)

[6]. New Delhi.pp.2

[7]. Patil, V.A. and Bangal, O.B. 1984. Influence of seed weight on germination and seedling vigor in safflower cultivars. Seed Res., 12(2): 104-106.

[8]. Patil, V.N and S.D Sarode. 1998. seed quality in wheat as influenced by specific gravity separation, Seed Res., 16 (1) : $114-116$.

[9]. Rajasekaran, R. 2001. Seed production, processing and storage studies in niger (Guizotiaabyrrinica L. f. cass.) cv. Paiyur 1, M.Sc. (Ag.) Thesis, Tamil Nadu Agricultural University, Coimbatore.

[10]. Rajasekaran, S. 1997. Seed technological studies in rice bean (Vigna umbellate Thunb).M.Sc (Ag). Thesis, Tamil Nadu Agricultural University, Coimbatore.

[11]. Radha, N.S. 1991. Studies on seed production, harvest date, processing and storage in Sesbaniarostrata, sesbaniaaculeata, and Tephrosiapurpurea. M.Sc. (Ag) Thesis, Tamil Nadu Agricultural University, Coimbatore.

[12]. Singh, H. and S.S. Gill. 1983. Effect of seed coat colour on seed germination of Okra.(abelmoschusesculentus L. Moench)

[13]. Singh. R.A., C.S. Tomar and R.S. Thakur. 1981. Effect of cobalt and molybdenum on germination of soybean seeds. Seed Res., 9(1): 73-75..

[14]. Srimathi, P. and K. Malarkodi. 2000. Influence of nutrient pelleting on seed yield of soybean cv. CO 1. Indian Agriculturist, 44 (1/2) : 79-82.

[15]. Srimathi, P. Malarkodi, K. Geetha, R. and V. Krishnaswamy. 2002. Nutrient pelleting to augment quality seed production in soybean. Seed Res., 30(2): 186-189.

[16]. Vakeswaran, V. 1998. Seed technological studies in pea (Pisumsativum). M.Sc (Ag.) Thesis, Tamil Nadu Agricultural, Coimbatore. 
Influence of Colour Grading on seed and seedling quality characters of Sesamum indicum

Table 1. Influence of colour grading on seed and seedling quality characteristics

\begin{tabular}{|c|c|c|c|c|c|c|c|}
\hline Colour grades & $\begin{array}{c}\text { Seed } \\
\text { recovery } \\
(\%)\end{array}$ & $\begin{array}{c}100 \text { seed } \\
\text { weight }(\mathrm{mg})\end{array}$ & $\begin{array}{c}\text { Germination } \\
(\%)\end{array}$ & $\begin{array}{c}\text { Root length } \\
(\mathrm{cm})\end{array}$ & $\begin{array}{c}\text { Shoot length } \\
(\mathrm{cm})\end{array}$ & $\begin{array}{c}\text { Dry matter } \\
\text { production } \\
10 \text { seedling } \\
(\mathrm{mg})\end{array}$ & Vigour index \\
\hline Black & 64 & 311 & $84(66.42)$ & 8.3 & 5.4 & 41.2 & 1150 \\
\hline Brown & 24 & 245 & $84(66.42)$ & 8.2 & 5.6 & 39.3 & 1159 \\
\hline Cream & 19 & 206 & $74(59.34)$ & 7.6 & 4.9 & 36.4 & $925^{-}$ \\
\hline Bulk & - & $303^{-}$ & $80^{-}(63.43)$ & 7.9 & 5.3 & 38.1 & 1056 \\
\hline $\mathrm{CD}(\mathrm{P}=0.0 \mathrm{5})$ & 0.760 & 0.002 & 1.719 & 0.182 & 0.214 & 1.121 & 1.537 \\
\hline
\end{tabular}

(Figures in parentheses are arc sine transformed values)

Fig: 1.Influence of colour grading on seed germination, seed recovery and vigour index

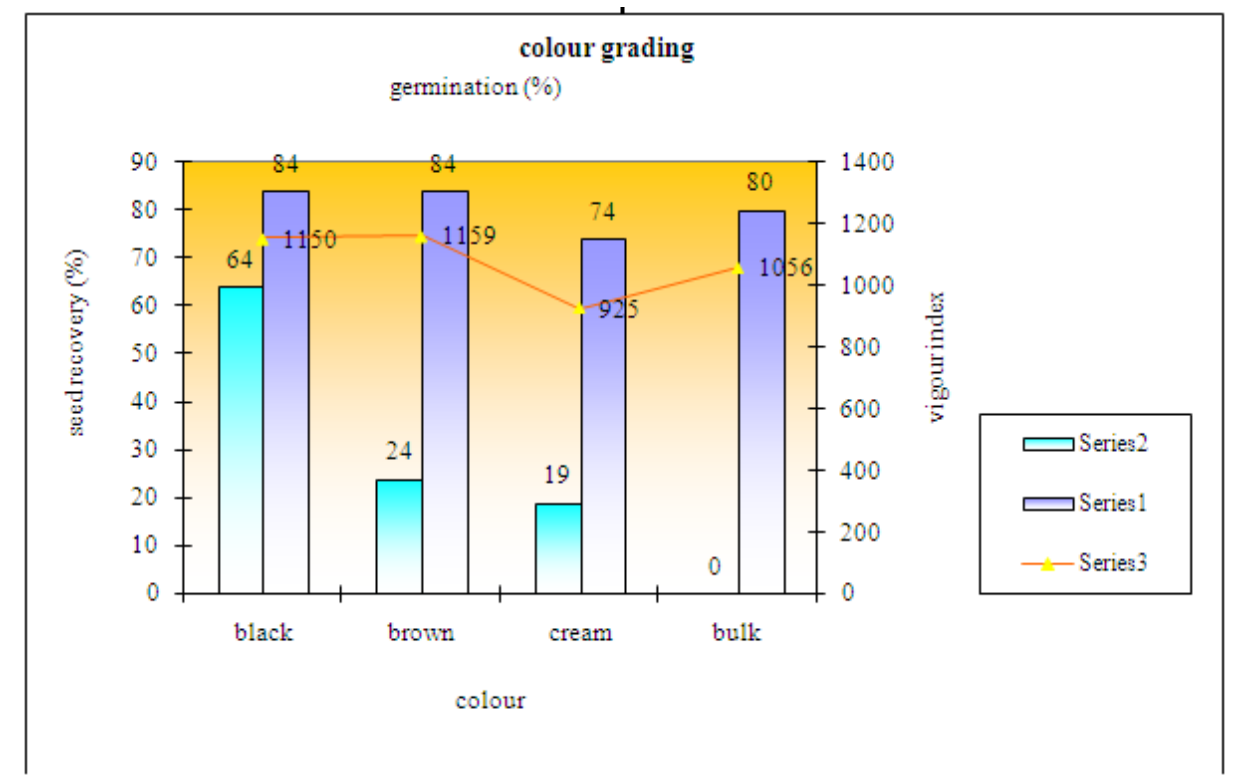

